\title{
Diagnosis of a small splenic artery aneurysm mimicking a gastric submucosal tumor on endo- scopic ultrasound
}

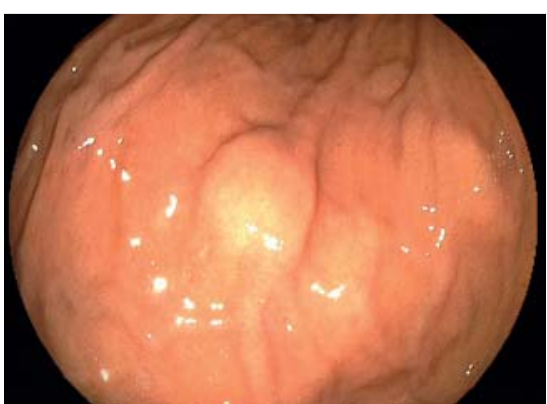

Fig. 1 Endoscopic view of a submucosal tumor on the posterior wall of the gastric fundus (patient 2). The lesion had an elastic consistency, and the overlying mucosa appeared smooth and intact. No arterial pulsations were noted.

Although extrinsic compression of the gastric wall by an intact splenic artery is a common observation, the characteristic endoscopic ultrasound (EUS) findings of small splenic artery aneurysm (SAA) have not yet been established.

We present four symptom-free patients who were diagnosed as having extragastric compression from a small SAA in the early stage, at the posterior wall of the fundus, by EUS. Table 1 summarizes the clinical characteristics of the patients and the findings of the various investigations. All patients underwent esophagogastroduodenoscopy (EGD), EUS using an electronic radial scanning echoendoscope

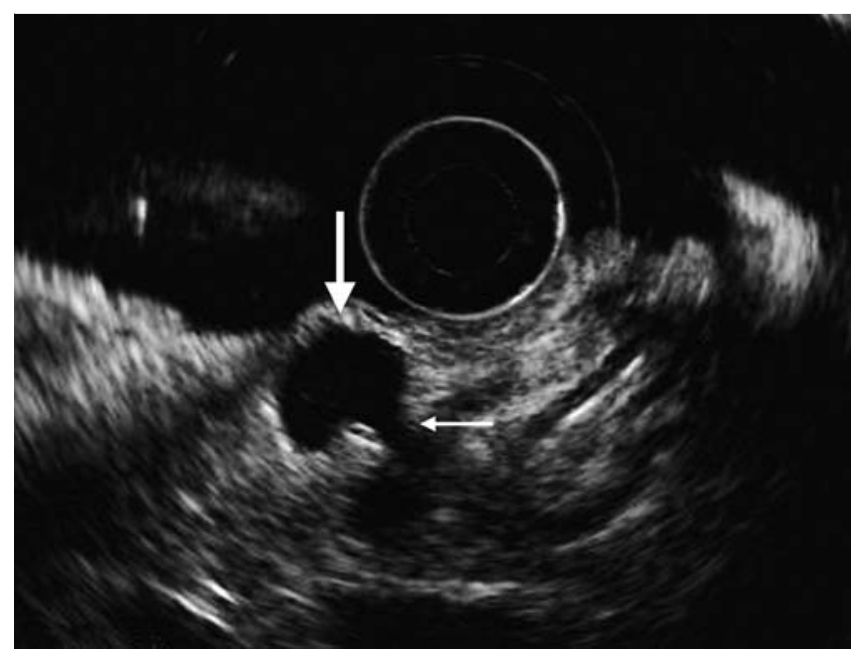

Fig. 2 Radial endoscopic ultrasound (EUS) image (grayscale) showing localized dilatation of the splenic artery (big arrow) and compression of the intact gastric wall (patient 2). The intact part of the splenic artery is also seen (small arrow). Intramural tumors can be differentiated from cysts or vessels by visualizing their layer of origin, echo pattern, and margins.

(EG-530UR, Fujifilm Corp., Saitama, Japan) with color and power Doppler flowmapping capabilities, and three-dimensional spiral computed tomographic angiography (3D-CTA) using intravenous contrast agents. The final diagnosis was based on the EUS and 3D-CTA findings and the results of the clinical follow-up (5-16 months, mean 12 months).

Screening EGD seemed to reveal a submucosal tumor on the posterior wall of the fundus in all the patients ( $\bullet$ Fig. 1). However, EUS revealed a normal gastric wall compressed by a focally dilated aneurysm ( Fig. 2), and an arterial pulsation signal was detected by pulse-wave Doppler ultrasound ( $\bullet$ Fig. 3). 3D-CTA revealed these submucosal masses to be small SAAs. Patient 2 had an aneurysm (15-mm diameter) at the hilum of the splenic artery ( $\bullet$ Fig. 4). There was no change in the SAAs in any of the patients at a 3-month follow-up with 3D-CT.

SAA is the most common visceral artery aneurysm [1,2], and although asymptomatic when small, $3 \%-10 \%$ of SAAs are at risk for rupture $[3,4]$. Aneurysms should be considered in the differential diagnosis of endoscopically detected submucosal lesions to avoid potentially

Table 1 Clinical characteristics of the patients and esophagogastroduodenoscopy (EGD), endoscopic ultrasound (EUS) and three-dimensional computed tomographic angiography (3D-CTA) findings.

\begin{tabular}{|c|c|c|c|c|c|c|c|c|c|}
\hline \multirow{4}{*}{$\begin{array}{l}\text { Patient (age } \\
\text { in years/sex) }\end{array}$} & \multirow[t]{4}{*}{ Symptoms } & \multirow{4}{*}{$\begin{array}{l}\text { EGD } \\
\text { findings }\end{array}$} & \multicolumn{4}{|c|}{ EUS findings } & \multicolumn{3}{|c|}{ 3D-CTA findings } \\
\hline & & & & & & \multirow{2}{*}{\multicolumn{4}{|c|}{$\begin{array}{l}\text { Doppler } \\
\text { Pulse-wave }\end{array}$}} \\
\hline & & & & & & & & & \\
\hline & & & SDS & CGW & $\begin{array}{l}\text { Size, } \\
\mathrm{mm}\end{array}$ & & Site & Form & $\begin{array}{l}\text { Size, } \\
\mathrm{mm}\end{array}$ \\
\hline $1(53 / F)$ & None & SMT & + & + & 10 & $\begin{array}{l}\text { Arterial } \\
\text { pattern }\end{array}$ & Hilum & Saccular & 10 \\
\hline $2(64 / M)$ & None & SMT & + & + & 15 & $\begin{array}{l}\text { Arterial } \\
\text { pattern }\end{array}$ & Hilum & Saccular & 15 \\
\hline $3(58 / F)$ & None & SMT & + & + & 11 & $\begin{array}{l}\text { Arterial } \\
\text { pattern }\end{array}$ & Hilum & Saccular & 10 \\
\hline $4(57 / F)$ & None & SMT & + & + & 10 & $\begin{array}{l}\text { Arterial } \\
\text { pattern }\end{array}$ & Hilum & Saccular & 10 \\
\hline
\end{tabular}

SMT, submucosal tumor; SDS, segmental dilatation of the splenic artery; CGW, compression of the gastric wall 


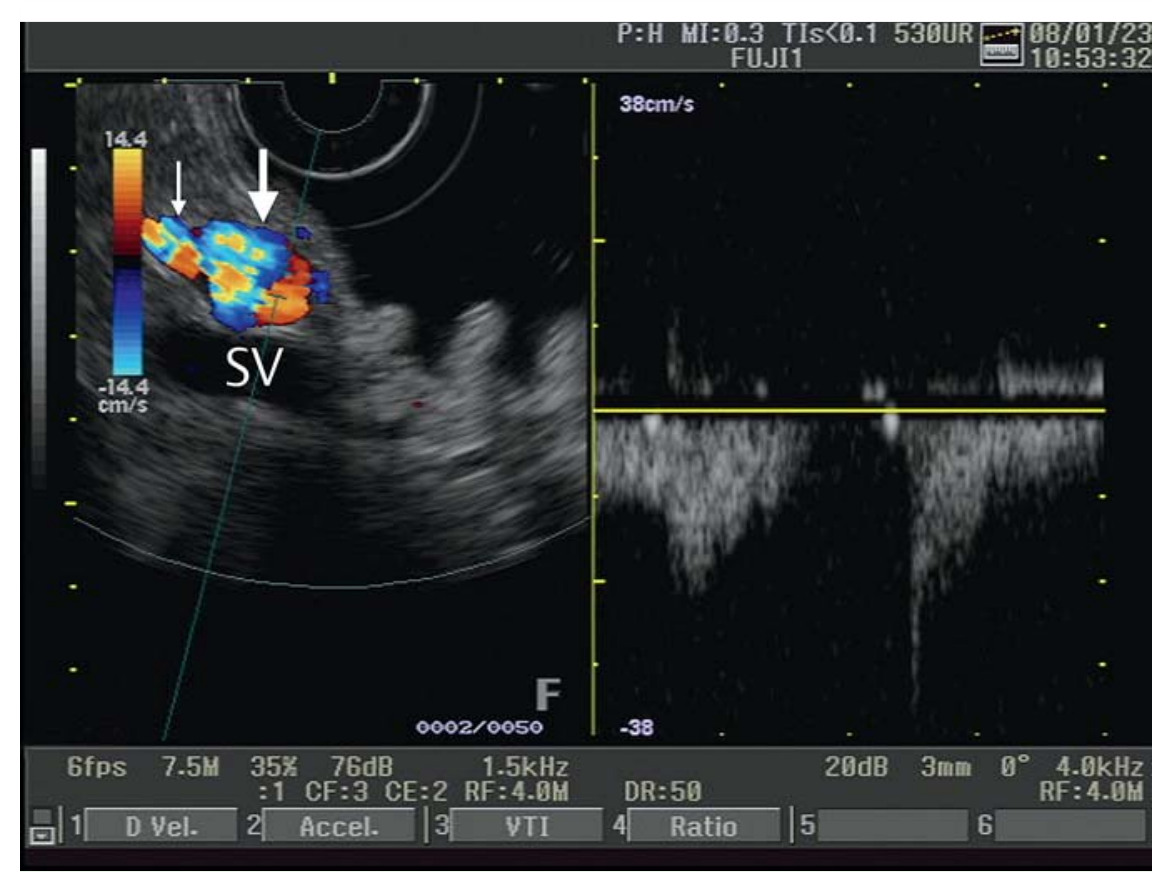

Fig. 3 Color and pulse-wave endoscopic ultrasound (EUS) showing the arterial flow and vascular nature of the lesion originating in the splenic artery (patient 2). In our series, we detected an arterial pulsating wave in all lesions using a pulse-wave Doppler EUS system. Arterial and venous flow are distinct, and therefore it is easy to differentiate splenic artery aneurysms from veins.

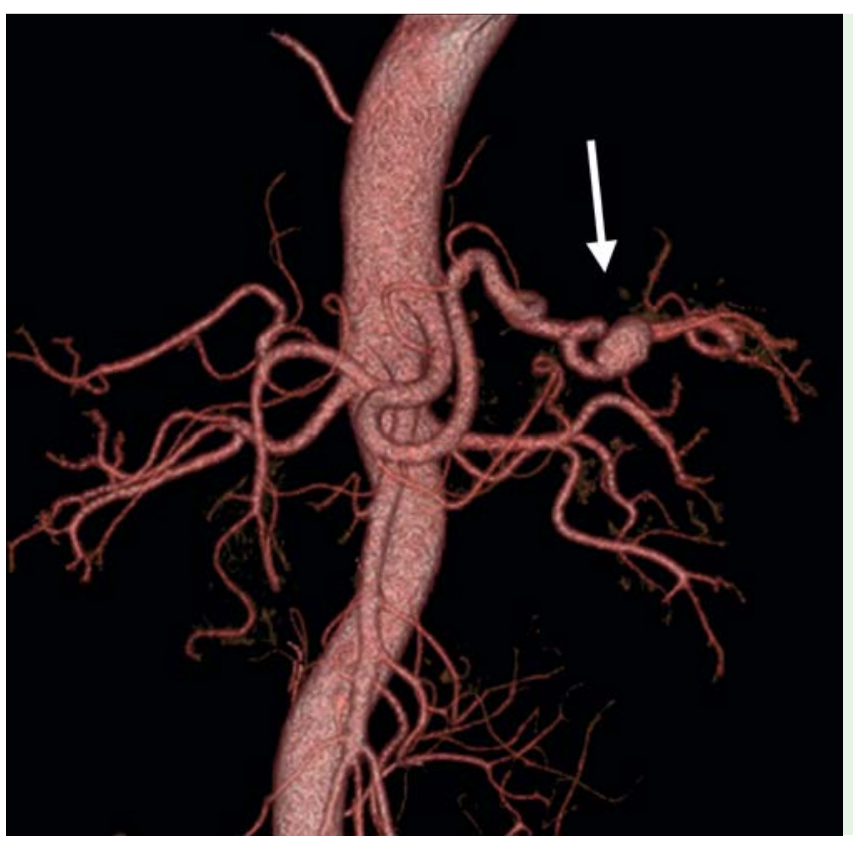

harmful outcomes of EUS-guided fine needle aspiration or biopsy. EUS may be a reliable initial diagnostic modality for the diagnosis of even small SAAs $(\leq 15-\mathrm{mm}$ diameter), primarily to differentiate between true submucosal tumors and extrinsic compression of the gastric wall caused by normal or pathological structures.

\section{Competing interests: None}

Endoscopy_UCTN_Code_CCL_1AF_2AD

N. Higuchi ${ }^{1}$, K. Akahoshi ${ }^{1}$, K. Honda ${ }^{1}$, N. Matsui ${ }^{1}$, M. Kubokawa ${ }^{1}$, Y. Motomura $^{1}$, K. Nakamura ${ }^{2}$, R. Takayanagi ${ }^{2}$

1 Department of Gastroenterology,

Aso lizuka Hospital, lizuka, Japan

2 Department of Medicine and Bioregulatory Science, Graduate School of Medical Sciences, Kyushu University, Fukuoka, Japan

\section{References}

1 Deterling RA Jr. Aneurysm of the visceral arteries. J Cardiovasc Surg 1971; 12: 309-322

2 Dave SP, Reis ED, Hossain A et al. Splenic artery aneurysm in the 1990s. Ann Vasc Surg 2000; 14: $223-229$

3 Stanley JC, Fry WJ. Pathogenesis and clinical significance of splenic artery aneurysms. Surgery 1974; 76: 898 - 909

4 Trastek VF, Pairolero PC, Joyce JW. Splenic artery aneurysms. Surgery 1982; 91: $694-$ 699

\section{Bibliography}

DOI $10.1055 / \mathrm{s}-0029-1243940$

Endoscopy 2010; 42: E107-E108

(c) Georg Thieme Verlag KG Stuttgart - New York . ISSN 0013-726X

\section{Corresponding author}

\section{K. Akahoshi, MD, PhD}

Department of Gastroenterology

Aso lizuka Hospital

3-82 Yoshio

lizuka 820-8505

Japan

Fax: +81-948-298747

kakahoshi2@aol.com 